\title{
Embodied Neurobiological Perspective on the Survey Study of Conceptual Metaphors of Chinese Eating Verb 吃 Chi 'Eating' Phrases
}

\author{
Sheue-Jen Ou \\ Department of Applied Foreign Languages, Hsuan Chuang University, Taiwan
}

Copyright $(2018$ by authors, all rights reserved. Authors agree that this article remains permanently open access under the terms of the Creative Commons Attribution License 4.0 International License

\begin{abstract}
Cognitive linguists believe that the proto-languages use the body as a reference to determine the environmental orientation, such as up and down, inside and outside as well as entrance and exit. However, there is lack of studies examining whether these theories are consistent with the views of the language users, such as the general public. This paper attempts to investigate the "Embodied Mind Theory" in cognitive linguistics by surveying the public view of Chinese 吃 Chi 'Eating' verb phrases in Taiwan. In addition, this paper also aims to shed the light on the possible links between embodied neurobiological pathways of eating and Chinese eating verb phrases.
\end{abstract}

Keywords Embodied Cognitive Linguistics, Chinese Verb Phrases, Neurobiology, Language Survey

\section{Introduction}

Cognitive linguists believe that the proto-languages use the body as a reference to determine the environmental orientation, such as up and down, inside and outside as well as entrance and exit. According to the embodied linguistics, the languages construct the abstract concepts by metaphorizing the higher one as being superior and lower one as inferior [1].For example, we metaphorize entering as accepting and exiting as refusing, which was discovered through mapping the domain of orientation to the domain of abstract ranking. However, there is a lack of studies examining whether these theories are consistent with the views of the language users such as the general public. Inspired by Meyers and Ko [2], this paper investigates the embodied mind theory through comparing the "eating" action from a neurobiological point of view with Chinese eating verb 吃 $C h i$ 'eating' and its phrases from the point of view of public language users. Specifically, the author poses the following research questions:

Eating is a basic daily action to ensure that humans survive. This action is involved with many human physiological processes, including muscle contraction, senses, brain functioning and requires the cooperation of many different human body parts. The language used to describe/construct eating in the brain areas may be triggered or linked to the "eating" action pathways throughout the body. Accordingly, how much or to what extent can the generation of Chinese eating phrases in the brain language regions be adjacent to these biological action regions due to the proximity relationship?

There are a vast number of Chinese phrases linked to eating verb 吃 $C h i$ 'eating'. How do we classify these phrases into different categories according to their related situations, such as human senses, food variety, social cultures and so on?

Are there any neural circuitry or pathways that are constructed to form mapping relations or conceptual metaphors between these idioms in the first place? If so, what are the possible relationships? Furthermore, what is the response of the language users when they encounter these idioms? How are these idioms understood? What possible parts of the neural circuitry or regions of ordinary Chinese speakers are triggered/ provoked?

What is the validity of the conceptual metaphor theory (by scholars) to general public readers? Can the general public survey results shed light on the theory?

This paper attempts to answer the above questions by aiming to extend the traditional meaning of "embodied" [1], which considers the whole body or organism as a unit. Instead, we have stretched this meaning to include the detailed neurobiological processes that occur involuntarily or unconsciously. In the second section, the paper reviews George Lakoff's traditional embodied cognition linguistics $[3,4]$. After this, the paper summarizes the neurobiological pathways involved with the "eating" action in the third section. In the fourth section, the paper reports and 
discusses the survey results on Chinese eating verb phrases in Taiwan. Finally, a summary of neurobiology, embodied cognitive linguistics and general public's view about eating verb phrases forms the conclusions of this paper.

\section{Background and Literature Review}

Perception and ideas are the most basic units of thought, which is similar to how cells are the basic unit of organisms. The word "concept" is made of "con" and "-cept." "Con-" refers to "together," while "-cept" is related to the root of per-cept-ion (understanding the innate feelings received). In other words, "concept" is about "integrating" various human perceptions or ideas.

The famous cognitive linguist George Lakoff [1] believes that conceptual metaphors in language are derived from the human body cognition. For example, the action of taking things in hand requires several steps to coordinate and complete according to Pinker [5]. The visual signal reaches the brain and stimulates muscles before the hands reach out to touch things to judge if the tactile feedback is expected or not. After this, the hands retract to be back near the body although this schema also produces some mapping of the conceptual metaphor at the same time, such as take a shot, take it seriously, cannot take eyes off of her, or take literal meaning etc.

If the human body is considered as the origin in spatial coordinates, some corresponding primary psychological spatial coordinates in the human brain are assigned to the surrounding objects. The body's movements are constantly recorded and stored in these primary coordinates [5]. Meanwhile there are other higher-level or different layers of mental coordinates in the brain. They may shift, map, copy or simulate the primary coordinate's movement programs and transform them into other coordinates, such as opportunity coordinates (take a shot); priority coordinates (take it seriously); and seeking partner's coordinates (cannot take eyes off of her) etc. [6].

According to Lakoff's theory of the integration of mind and matter, it seems that some of the source or target domains are defined by the brain or some part of the body that is actively involved in performing these functions. In his theory of neural metaphorical system, Lakoff cited an example of "smell fishy" by the following conceptual steps [6]:

1. Morality is pure and clean while immorality is rotten. Life experience indicates that pure food relates to good but rotten food is related to illness.

2. Understanding involves digesting external input information. Smell is a type of external perception and feeling or smelling a fish is an understanding.

3. Getting what one wants is to achieve one's goal, while getting what one does not desire means being in trouble. Rotten fish is something that one does not want.

4. Suspicion is an understanding, awareness or feeling that the others have committed unethical behavior prevents a skeptic from reaching their goal.

Accordingly, this biological basis theory leads us to discuss the "eating" in neurobiological pathways in the next section.

\section{3. "Eating" Biological Pathways}

This paper attempts to extend the traditional "embodied" concept which describes a whole container/organism perspective, to a more detailed view involving interactions between mutual parallel systems inside the body. This may provide more insights into biological mechanisms and transform them into meaningful interpretations of Chinese eating verb phrases. The following is a review about human eating processes, which are divided into three subsections: food intake and its movement in the digestion tract; the triggering of senses by food-associated properties and their neural pathways through the thalamus to brain cortex; and the feedback from the body into lateral hypothalamic area (LHA) according to Marieb and Hoehn [7].

Eating is a very complicated process, which involves the environment, lifestyle, individual predisposition (genetic wiring), neural process control, visceral organs interaction, biofeedback and so on as illustrated in Figure 1 [8]. In this figure, the cognitive and emotional brain refers to the thalamus area and above it, while the metabolic brain refers to the hypothalamus region and below it in the brain. 


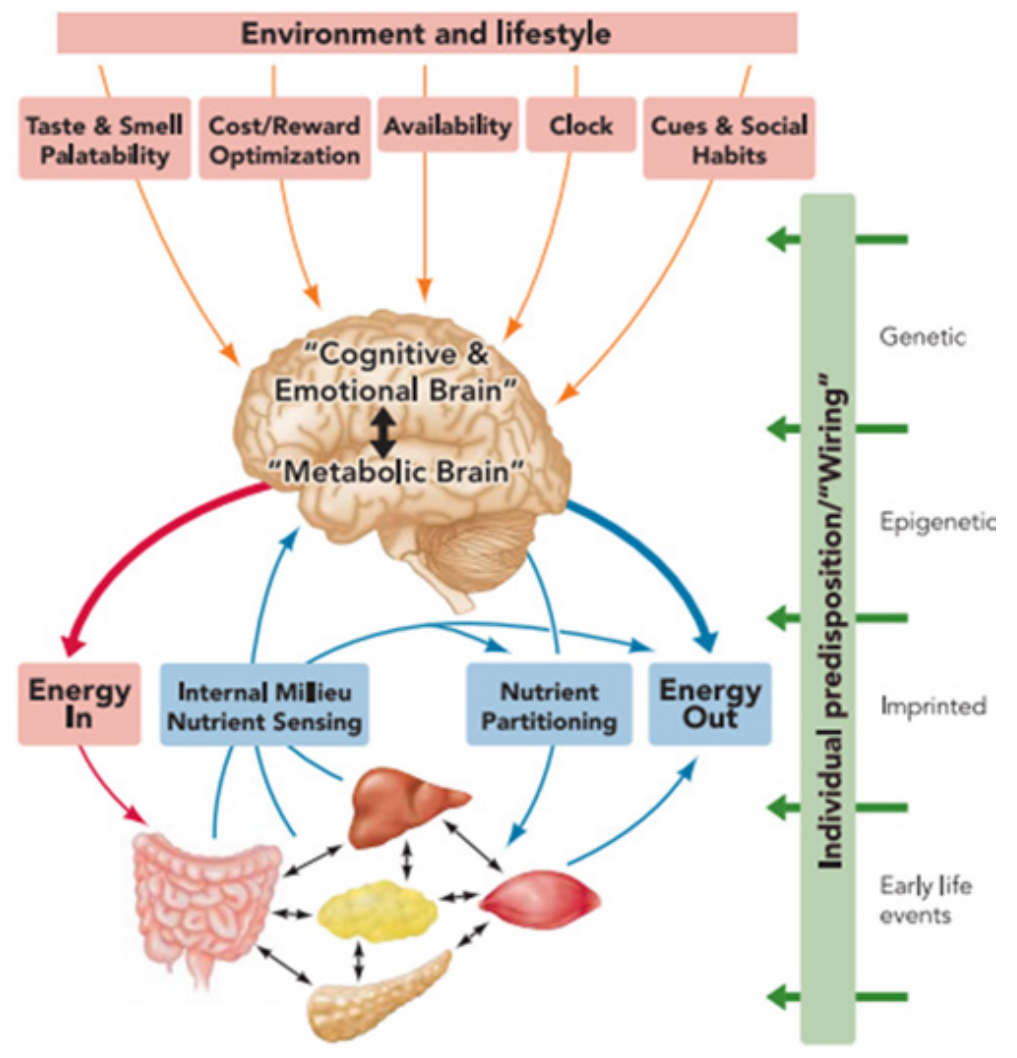

Figure 1. Schematic diagram showing the major factors determining neural control of appetite and regulation of energy balance [8].

\subsection{Physiological Process Model of "Eating"}

Eating and swallowing are complex behaviors that involve the volitional and reflexive activities of more than 30 nerves and muscles [8]. The Process Model includes three stages: (1) Oral Stage: the tongue carries the food to the post-canine region and rotates laterally, before starting the food processing by reducing the size of food particles by mastication. This is softened by salivation until swallowing. During this period, the cyclic movement of the jaw in processing is coordinated with the movement of the tongue, cheek, soft palate and hyoid bone. At the same time, the movements of the jaw and tongue pump air into the nasal cavity through the pharynx, delivering the food's aroma to chemoreceptors in the nose. Finally, the food is placed on the tongue surface and propelled back through the faucets to the oropharynx. This stage can be interposed with food processing cycles. (2) Pharyngeal Stage: The Pharyngeal swallow is a rapid sequential activity. It has two biological features: (i) food passage, propelling the food bolus through the pharynx and upper esophageal sphincter (UES) to the esophagus and (ii) airway protection, isolating the larynx and trachea from the pharynx. (3) Esophageal Stage: The esophageal is a tubular structure from the lower part of UES to the lower esophageal sphincter (LES), which is also tensioned at rest to prevent regurgitation from the stomach. It relaxes during a swallow and allows the bolus to pass to the stomach. Once the food enters the esophagus past the UES, a peristalsis wave carries the bolus down to the stomach through the LES [9].

This model is consistent with a Chinese verb phrase 囫㽞吞東 Huluntunzao 'swallowing the whole dates' (which literally means that a person swallows whole dates, namely, that he/she laps up information without digesting it) in the biological sense. Furthermore, it conceptually metaphorizes this phrase to a way of handling knowledge in an abstract sense.

It is also interesting to know that this model provides an embodied biological basis for a Chinese idiom 食古不化 Shigubuhua 'swallowing ancient learning without digesting it.' In an abstract sense, this means someone who is fettered by old conventions.

\subsection{Neurobiological Pathways of "Eating"}

Signals from the nerve fibers of the taste buds travel via the cranial nerves VII, IX and X to the tract nucleus solitarius (gustatory area) located in the posterior brain stem [7].From here, the neurons transmit signals to the thalamus (ventral posterior medial nucleus). After this, third order neurons carry signals to the postcentral gyrus in the parietal cerebral cortex (gustatory cortex). Essentially, the thalamus relays the information to the primary gustatory cortex located in the somatosensory cortex. The primary gustatory cortex is where the perception of a particular taste is processed, as illustrated in Figure 2 [7]. 

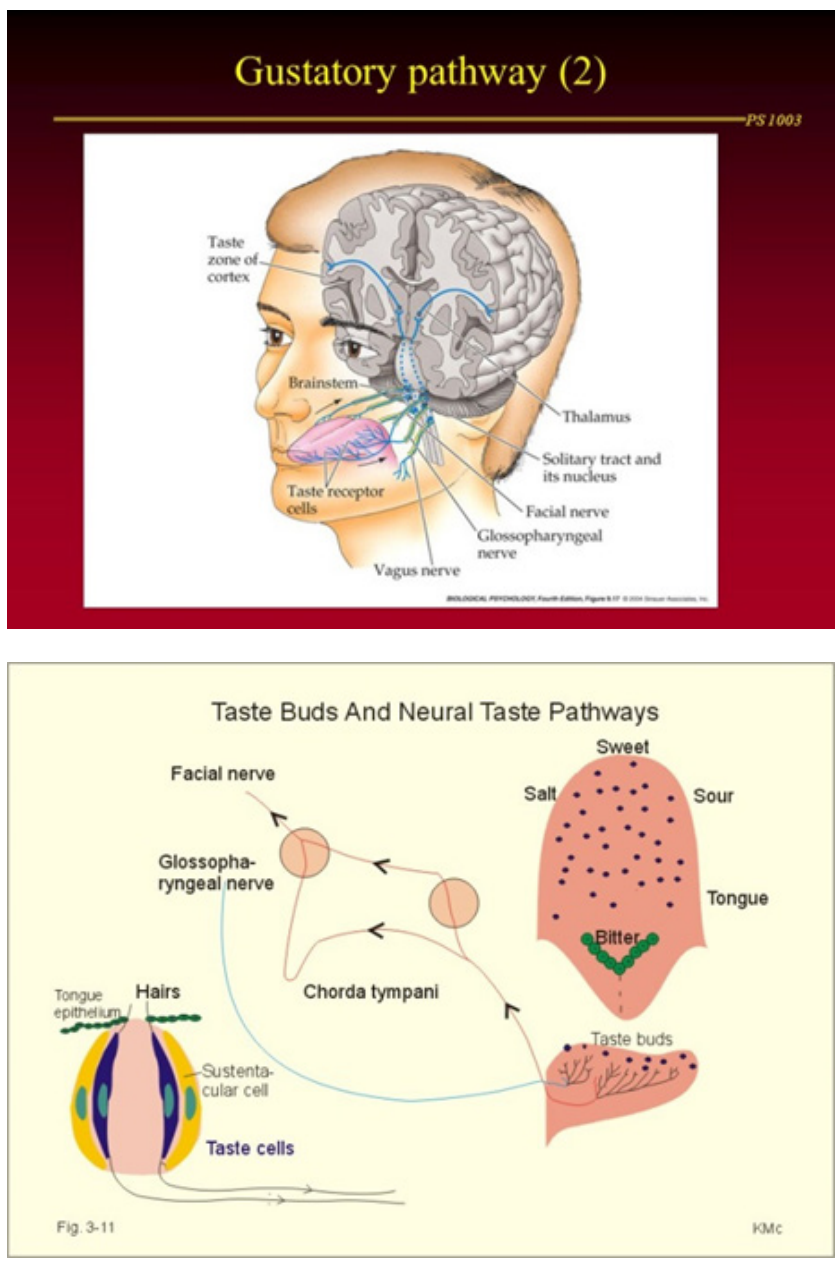

Figure 2. Signals from the nerve fibers of the taste buds travel via cranial nerves VII, IX and X to the tract nucleus solitarius (gustatory area) located in the posterior brain stem [7]

Some taste signals that are transmitted into the thalamus trigger the salivatory nuclei, which stimulate the salivary glands (parotid, submandibular and sublingual). This taste reflex is the reason for salivating when eating and why certain tastes trigger copious saliva secretion. This is consistent with a Chinese idiom 重涎欲滴 Chuixianudi 'drooling', which means that delicious food makes somebody's mouth water.

The primary gustatory cortex is a brain structure responsible for the perception of taste. It consists of two substructures: the anterior insula on the insular lobe and the frontal operculum on the inferior frontal gyrus of the frontal lobe, as illustrated in Figure 3 [7].Due to its composition, the primary gustatory cortex is sometimes referred to as the $\mathrm{AI} / \mathrm{FO}$ (Anterior Insula/Frontal Operculum) in literature. By using extracellular unit recording techniques, scientists have elucidated that the neurons in the $\mathrm{AI} / \mathrm{FO}$ respond to sweetness, saltiness, bitterness and sourness, and they code the intensity of the taste stimulus [7].

As a side note, the olfactory cortex of the smell is near to the gustatory cortex. Both the skin touch senses and taste buds are under the control of the primary somatic sensory cortex and sensory association area as shown in Figure 4 below. This implies that the taste sense might be related to touch and vision, such as 吃又濑又白的豆腐 Chi you nen you bai de dou fu 'eating a soft and a fair skin-like tofu or bean curd' in a Chinese idiom.
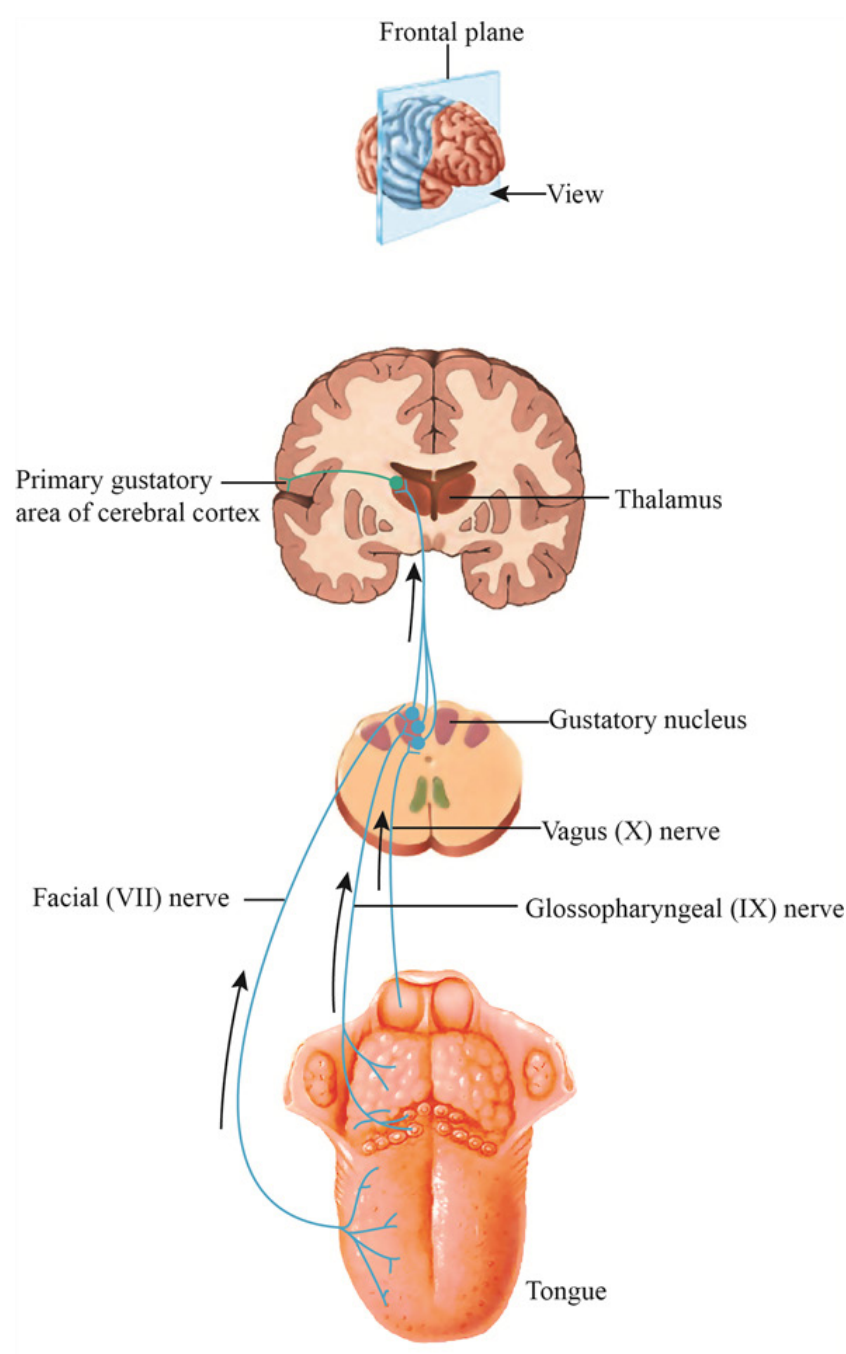

Gustatory pathway

\section{The Insular Cortex}

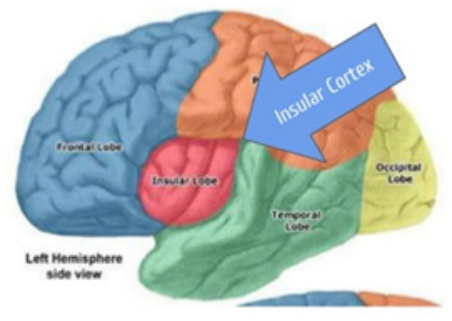

Figure 3. The gustatory pathway. The blue line indicates the gustatory pathway to cortex [8]. 


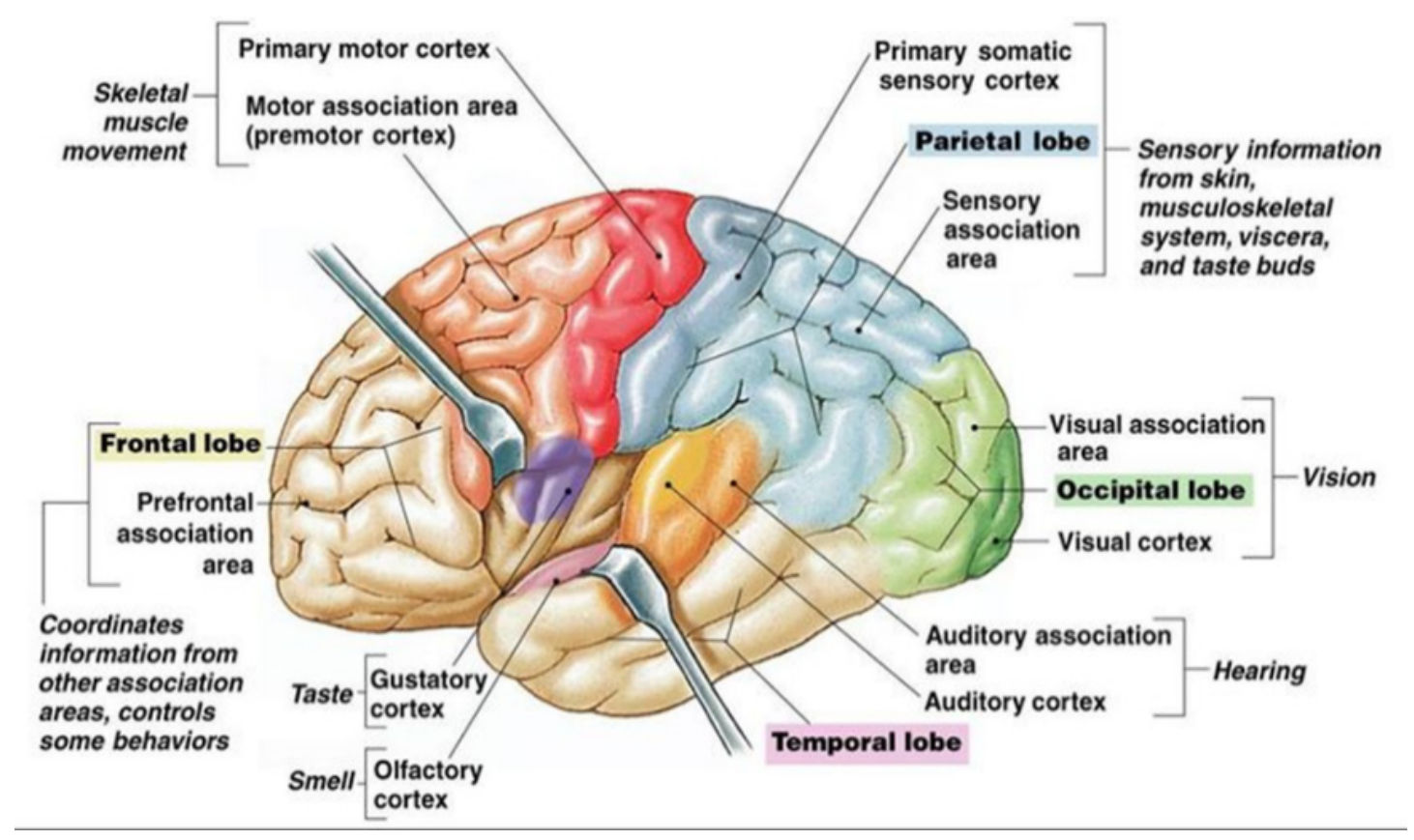

Figure 4. Detailed brain lobes [7].

After this, the cortex area sends a signal down to stomach and intestine to simulate the secretion of gastric juices to assist with digestion. Overall, the somatic nervous system controls the oromotor movements of eating, while the autonomic nervous system controls the movements of digestive tract through its effects on enteric nervous system, intraluminal digestion and neuro-endocrine release resulting in metabolic transformations [10].

\subsection{Bio-Feedback pathway controlled by hypothalamus}

Eating can be initiated by a variety of external stimuli, such as visual, olfactory, auditory, reward and social. Most of time, they act as positive feedback. However, internal stimuli, such as a slight decrease in plasma glucose, a rise in liver temperature, and a decrease in basal metabolism, are also effective in affecting eating. In other words, eating is under feedback control from internal stimuli once simulated, which is mostly negative feedback. Where does this control come from?

The normal control of food intake and body weight by the brain relies upon the detection and integration of signals, which reflects energy stores and fluxes and their interaction with myriad inputs that are related to food palatability and gastrointestinal handling as well as social, emotional, circadian, habitual and other situational factors [9]. The hypothalamus is involved in many functions of the autonomic nervous system as it receives information from nearly all parts of the nervous system. As such, it is considered as the link between the nervous system and the endocrine system.

Namely, the hypothalamus helps to stimulate or inhibit many of human body's key processes. One of these is the glandular secretions of the stomach and intestines.

The hormones of the endocrine pancreas interact with receptors at many points along the gut-brain axis, which stretches from the liver to the sensory vagus nerve to the hindbrain to the hypothalamus. Their signals are conveyed both in neural and humoral pathways. Finally, their actions include gastrointestinal, metabolic and behavioral effects.

If so, how does the hypothalamus control the feedback system? The hypothalamus has the greatest concentration of nuclei at which set points, which are similar to the thermostat in the house, are monitored and controlled. Thus, the hypothalamus can be considered as the key brain region for the control of homeostasis. Physiological set points refer to the baseline level at which functions, such as heart rate, and chemical compositions, such as plasma sodium concentration, are normally maintained. These data are transmitted to the central nervous system and affect the discharge rate of set point neurons in hypothalamic nuclei. These set points are represented in the brain by specific discharge rates in the neurons dedicated to the monitoring and control of specific physiological processes.

In particular, the Lateral Hypothalamic Area (LHA) seems to sense pre-absorptive satiety (i.e., in advance of intestinal absorption). Feeding is known to stop long before the nutrients are absorbed and their constituent molecules, such as glucose, free fatty acids and amino acids, have entered the metabolic machinery.

These changes in the discharge rate result in altered hypothalamic efferent outflow and hence, cause a change in the functions of regulatory systems. In particular, the lateral hypothalamic area (LHA) acts as a hub for the integration of diverse central and peripheral signals. Through complex local and long-range output circuits, the LHA coordinates adaptive behaviors to regulate the system 
and response to the environment. In summary, positive feedback is from sensory inputs, such as smell, but negative feedback comes from LHA $[11,12]$.

Here, these feedback mechanisms are included in a Chinese idiom 眼䭒肚飽 Yanchan du bao 'Eyes is bigger than belly.' Conceptually it metaphorizes to someone being insatiably greedy. Essentially, 眼餽 Yanchan 'eyes are hungering' is due to the positive visual sensory input, while 肚飽 $d u$ bao 'belly is full' is the negative feedback from the blood glucose signal to LHA. Unfortunately, the latter negative signal occurs later, and is delayed or weaker than the first signal and fails to catch up with the first positive signal.

\section{Language Survey and Results}

The majority of research on embodied cognitive linguistics is often limited to the experts' theoretical interpretations. This paper has considered a neurobiological point of view for the "eating" action and tried to shed some light on extending the meaning of embodied cognitive linguistics on Chinese eating verb phrases. In the remaining section, we provided the results and its explanations of a questionnaire survey on "eating" verb phrases created for the modern general public. The survey includes two parts: (1) rather than the original meaning of eating action, 吃 Chi 'eating' has been extended to other meanings, such as 'bearing,' 'absorption,' 'dependence,' 'eliminating,' 'entering,' 'consuming,' 'comprehending' and 'acquisition' according to Nie [13].A group of students were surveyed on their opinions on ordering these meanings based on personal preference and (2) their immediate responses when they encounter some Chinese eating verb phrases.

\subsection{Survey results of the primary and extended meanings of 吃 Chi 'Eating' and their implications}

Completed questionnaires for this study were collected from 29 students in a class at a University in Southern Taiwan in the spring of 2018. They were all adult students from southern region of Taiwan, and aged between 20 and 55 years old, with 13 female and 16 male students involved in the study. Every student had completed high school education, that is, they all had at least 12 years in Chinese language education. In addition to the basic meaning of action verb of 'eating,' the surveyed students were provided with a list of eight other possible meanings cited from a dictionary: 吸收Xishou 'absorbing,' 獲取 Huoqu 'acquisition,'承受 Chengshou 'bearing,'領會 Linghui 'comprehending,' 耗費 Haofei 'consuming,'進人 Jinru 'entering,' 消滅 Xiaomie 'extirpating,' and 依靠 Yikao 'relying.' The students were asked to prioritize these extended meanings by assigning a value from 1 to 8.The results are shown in Table 1 below:
Table 1. Statistical data on prioritizing extended meanings of 吃 Chi 'Eating'

\begin{tabular}{|c|c|c|}
\hline Extended meaning & $\begin{array}{c}\text { Mean assigned } \\
\text { value }\end{array}$ & $\begin{array}{c}\text { Square } \\
\text { deviation }\end{array}$ \\
\hline 吸收Xishou 'absorbing' & 2.34 & 1.51 \\
\hline 進入 Jinru 'entering' & 2.62 & 1.90 \\
\hline 承受 Chengshou 'bearing' & 4.07 & 2.21 \\
\hline 獲取 Huoqu 'acquisition' & 4.20 & 2.06 \\
\hline 耗費Haofei 'consuming' & 4.87 & 1.78 \\
\hline 依靠 Yikao 'relying' & 4.93 & 2.43 \\
\hline 領會Linghui 'comprehending' & 5.69 & 1.84 \\
\hline 消隇Xiaomie 'extirpating' & 5.79 & 2.07 \\
\hline
\end{tabular}

The data indicates that 'absorbing' and 'entering' are ranked as the first two since they are very close to the original embodied meanings of 'eating.' If the body is like a container, the action of 'eating' has the meaning of 'taking in.' 'Bearing' and 'acquisition' are ranked in the next most popular group because they have been involved to a higher level of abstraction as even 'acquisition' is very close to the meaning of 'entering.' 'Consuming' and 'relying' are placed in the third group. It is reasonable that 'comprehending' is placed at the last group because its meaning is too far away from 'eating.' However, it is surprising that 'extirpating' is not popular because 吃光 Chi guang 'eat up' and 吃盡 Chi jin'eat out' are very common terms in Chinese. For example, 吃老本 Chilaoben 'live off one's old achievements or rest on one's laurels' is a very common phrase in Chinese. Interestingly, this is also in contrast with the linguist Newman's claim [13] that 'eating' has the meaning of 'destruction' or 'disappearance' of the entity consumed. In other words, the embodied meaning has resulted in objectification from the public's view.

The square deviations represent the survey's statistical distribution and the results indicate that the consensus of 'absorption' is very concentrated, which is followed by 'consumption.' However, 'relying,' such as 吃老本 Chilaoben 'live off one's old achievements or rest on one's laurels' gains the most varied opinions, which is consistent with the lower ranking as mentioned above.

\subsection{Survey results of 'eating' verb phrases and their implication}

The second part of the survey is about the degree of consensus on eating idioms: 吃香 Chixiang 'eating incense/aroma' suggests someone living it up, 吃醋 Chicu 'eating vinegar' represents jealousy and 吃苦 Chiku 'eating bitterness (difficulty)' are related to olfactory and taste buds; 吃豆腐 Chi doufu 'eating tofu or bean curd (taking advantage of females)' is related to tactile and visual senses; 吃閉門美 Chibimengeng 'eating closed door's soup (cold-shoulder treatment)' is about a food dish; 吃案子 Chi anzi 'eating a case (cover up a case)' and 吃䍗' 單 Chi fadan 'eating a ticket (eating a traffic ticket)' refer 
to law regulation; 吃回扣 Chihuikou 'eating kickbacks (accept commission)' and 吃老本 Chiloaben 'eating one's laurels(live off one's old achievements)' are regarding to business; and 吃力 Chili 'eating a laborious task' and 吃驚 Chijing 'eating surprise' are terms associated with physiology. The original questionnaire has 25 idioms. Other than aforementioned, the remaining idioms are 吃紅 Chihong 'eating red, profit sharing', 吃 軟不吃硬 Chi ruan bu chi ying éating soft but not eating hard, can be persuaded by reason but not be cowed by force', 吃鴨蛋 Chi yadian 'eating duck eggs, getting a zero on a test', 吃軟飯 Chi ruanfan 'eating soft rice, a kept man', 吃花酒 Chi huajil 'eating flower-flavored wine, to go to a dinner party with courtesans in attendance with drinking', 吃錯藥 Chi cuo yao 'take the wrong medicine, got up on the wrong side of the bed', 吃大鍋飯 Chi daguofan 'eating from the same big pot of rice, getting an equal share regardless of the work done', 坐吃山崩 Zuo chi shangbeng 'by idleness and eating, wealth dwindles away', 吃裏扒外Chi li pa wai 'eating inside while keeping things to outsider, live off someone while secretly helping others', 吃雐 Chikui 'suffers losses, come to grief', 吃癒 Chibie 'eating flatness, get coned.'
However, due to the limited space, this paper only discusses 11 items as described above. The survey results are listed below in Table 2 .

In general, most idioms receive consensus of about $85 \%$ or more if both the first and the second choices are combined since these two interpretations are not ridiculously different in meaning. The only big difference between the first two opinions is \#2 吃香 Chixiang 'eating incense (live it up or popular)' since a significant proportion (about 1/5) of surveyed students consider it as an actual eating action instead of a conceptual metaphor by convention. Similarly, $11 \%$ of the students consider \#7 吃 豆腐 Chi doufu 'eating tofu' as a real dish of food. Furthermore for \#3 吃醋 Chicu 'eating vinegar (jealous)' $7 \%$ of the students replied with an alternative meaning although this is a very popular expression of jealous in Chinese. The common factor of these three items seems that they are all involved with the concrete taste or dish, which might distract students from conceptual metaphors. In contrast, other items are more abstract, which automatically causes surveyed students to choose the metaphoric meaning.

Table 2. Survey opinion statistical distribution

\begin{tabular}{|c|c|c|c|c|c|}
\hline Categories & Idioms & \multicolumn{4}{|c|}{ Survey opinion statistical distribution } \\
\hline \multirow{3}{*}{$\begin{array}{l}\text { Olfactory and } \\
\text { taste buds }\end{array}$} & $\begin{array}{l}\text { \#2 吃香 Chixiang } \\
\text { 'eating incense } \\
\text { (live it up or } \\
\text { popular)' }\end{array}$ & $\begin{array}{l}63 \%-\text { At an } \\
\text { advantage }\end{array}$ & $\begin{array}{c}21 \% \text { - Delicious } \\
\text { meal }\end{array}$ & $8 \%$-Sharing & $\begin{array}{c}\text { 8\%-Pick a great } \\
\text { boss }\end{array}$ \\
\hline & $\begin{array}{l}\text { \#3 吃醋 Chicu } \\
\text { 'eating vinegar } \\
\text { (Jealous)' }\end{array}$ & $89 \%$-Jealous & $\begin{array}{c}3.7 \%- \\
\text { Regimen } \\
\text { (Self-cultivation) }\end{array}$ & $\begin{array}{c}3.7 \%- \\
\text { Misunderstanding }\end{array}$ & $\begin{array}{l}3.6 \% \text { - Facial } \\
\text { expression }\end{array}$ \\
\hline & $\begin{array}{l}\text { \#4 吃苦 Chiku } \\
\text { 'eating bitterness' }\end{array}$ & $\begin{array}{c}74 \%- \\
\text { Working hard }\end{array}$ & $\begin{array}{l}\text { 13\%- There are } \\
\text { always ups and } \\
\text { downs in life }\end{array}$ & $\begin{array}{c}9 \%- \\
\text { Chinese medicine, bitter } \\
\text { gourd }\end{array}$ & $4 \%$-Eat up \\
\hline Tactile & $\begin{array}{c}\text { \#7 吃豆腐 Chi } \\
\text { doufu } \\
\text { 'eating tofu' } \\
\end{array}$ & $\begin{array}{l}78 \% \text { - Harassment } \\
\text { of females by males }\end{array}$ & $\begin{array}{c}11 \% \text { - Food, } \\
\text { preserved eggs, soup }\end{array}$ & $\begin{array}{c}7 \%- \\
\text { Workplace, public places }\end{array}$ & $\begin{array}{c}4 \%- \\
\begin{array}{c}\text { Tofu shop pretty } \\
\text { hostess }\end{array} \\
\end{array}$ \\
\hline Food & $\begin{array}{l}\text { \#9 吃閉門美 } \\
\text { Chibimengeng } \\
\text { 'eating closed } \\
\text { door's soup' }\end{array}$ & $\begin{array}{l}75 \% \text { - Being refusal } \\
\text { or rejected }\end{array}$ & $\begin{array}{c}12.5 \% \text { - Salesperson, } \\
\text { business }\end{array}$ & $\begin{array}{c}8.5 \% \text { - Food is (temperature) } \\
\text { hot }\end{array}$ & $\begin{array}{c}4 \%- \\
\text { Mediation or } \\
\text { coordination }\end{array}$ \\
\hline \multirow[b]{2}{*}{ Legal } & $\begin{array}{c}\# 15 \text { 吃案子 } C h i \\
\text { anzi 'eating a case' }\end{array}$ & $69 \%$ - Cover up & $\begin{array}{l}15 \% \text { - Police, } \\
\text { government }\end{array}$ & $12 \%$-Stealing from thieves & $\begin{array}{c}4 \%-A s k \text { for } \\
\text { bribes }\end{array}$ \\
\hline & $\begin{array}{c}\text { \#16 吃罰單 } C h i \\
\text { fadan 'eating a } \\
\text { ticket' }\end{array}$ & $52 \%$-Violation & $\begin{array}{c}39 \%- \\
\text { Received a ticket }\end{array}$ & $4.5 \%$ - Not responsible & $\begin{array}{l}4.5 \% \text { - Illegal } \\
\text { case handling }\end{array}$ \\
\hline \multirow{2}{*}{ Business } & $\begin{array}{c}\# 18 \text { 吃回扣 } \\
\text { Chihuikou 'eating a } \\
\text { commission' }\end{array}$ & $88 \%$ - Kickbacks & $\begin{array}{c}\% \text { - Do not leave } \\
\text { traces while } \\
\text { cheating }\end{array}$ & $4 \%$ - Internet users & 4\%-Demanding \\
\hline & $\begin{array}{c}\# 14 \text { 吃老本 } \\
\text { Chilaoben 'eating } \\
\text { one's laurels' }\end{array}$ & $\begin{array}{l}60 \% \text { - Spending all } \\
\text { of one's nest egg }\end{array}$ & $36 \%$ - Out of income & $4 \%$ - Out of savings & \\
\hline \multirow{2}{*}{ Physiology } & $\begin{array}{c}\text { \#22 吃力 Chili } \\
\text { 'eating a hard task' }\end{array}$ & $52 \%$ - All-out effort & $\begin{array}{c}19 \% \text { - Difficult to } \\
\text { deal with }\end{array}$ & $14.5 \%$ - Overloading & $\begin{array}{l}\text { 14.5\%- Work, } \\
\text { effort, gym }\end{array}$ \\
\hline & $\begin{array}{l}\text { \#23 吃驚 Chi jing } \\
\text { 'eating a surprise' }\end{array}$ & $79 \%$ - Startled & $\begin{array}{c}21 \%-\text { Catch } \\
\text { someone off guard }\end{array}$ & & \\
\hline
\end{tabular}




\section{Conclusions}

The embodied cognitive linguist George Lakoff [1] pioneered the study of conceptual metaphor as he argued that there is a mapping relation between human body and abstract concept construction in language. $\mathrm{He}$ even progressed to include the neural substrate and computation in his theory later although he barely touched the aspect of neuropsychology $[3,6,15]$ and notwithstanding neurobiology. This paper contributes to the embodied mind theory in two ways: (1) the first paper proposes to include humans' detailed neurobiological aspect of 'eating' into the linguistics and (2) the first paper suggests including the public language users' opinions instead of listening to linguists' expertized theories or interpretations. We discovered many neurophysiological meanings of Chinese eating verb phrases, such as 眼鮧肚饱 Yanchan $d u$ bao 'Eyes is bigger than belly,'垂涎欲滴 Chuixianyudi 'mouth watering,' or 囫图吞妻 Huluntunzao 'swallowing the whole dates.'Furthermore, we discovered that it is easier to understand the abstract verb phrases, while there are more varied opinions on concrete verb phrases such as \#2 吃香 Chixiang and \#7 吃豆腐 Chi doufu. In the future studies, the author recommends an EEG or ERP study on the general public's responses to these verb phrases.

Funding: This research received no external funding

Conflicts of Interest: The authors declare no conflict of interest.

\section{REFERENCES}

[1] G. Lakoff, M. Johnson. Metaphors We Live By, University of Chicago Pres, 2003.

[2] J.Myers, Y.Ko. An experimental test of the temporal sequence principle in Chinese, The seventh international conference on cognitive science, August 17-20, 2010. Online available fromhttp://www.ccunix.ccu.edu.tw/ lngpr oc/MyersKo_ICCS2010.pdf

[3] G. Lakoff. The Neural Theory of Metaphor, in the Cambridge Handbook of Metaphor and Thought, 2nd ed. Edited by Raymond Gibbs. Cambridge University Press, pp .17-38, 2008.

[4] F. Ungerer, H-J. Schmid. An Introduction to Cognitive
Linguistics, Pearson Education Limited, 2009.

[5] S. Pinker. The Language Instinct: how the mind creates language, Harper Perennial Modern Classics, 2000.

[6] G. Lakoff. Mapping the brain's metaphor circuitry: metaphorical thought in everyday reason, Frontiers in Human Neuroscience: 8, 958, 2014. Online available from Doi: $10.338 \mathrm{a} /$ fnhum.2014.00958.

[7] E. N. Marieb, K. Hoehn. Human Anatomy \& Physiology. Pearson, 2013.

[8] G. J. Tortora, B. H. Derrickson. Principles of Anatomy \& Physiology, Wiley, 2011.

[9] H. Zheng, H-R. Berthoud. Neural Systems Controlling the Desire to Eat: Mind Versus Metabolism. Physiology, 23: 75-83, 2008. Online available from https://www.physiology.org/doi/pdf/10.1152/physiol.0004 7.2007 .

[10] G. Smith, N. Geary. The Behavioral Neuroscience of Eating. In Neuropsychopharmacology: The Fifth Generation of Progress. Edited by Kenneth L. Davis, Dennis Charney, Joseph T. Coyle, and Charles Nemeroff. American College of Neuropsychopharmacology, 2002. Online available fromhttps://acnp.org/wp-content/uploads/ 2017/11/C115_1665-1674.pdf

[11] E. M. Stricker, S. C. Woods. Handbook of Behavior Neurobiology, Vol 14, Neurobiology of Food Intake and Fluid Intake, 2nd Ed, Kluwer Academic/ Plenum Publishers, 2004.

[12] S. C. Woods, D. A. D'Alessio. Central Control of Body Weight and Appetite, J. Clin Endocrinol Metab. Nov. 93: S37-S50, 2008. Online available from https://www.ncbi.nlm.nih.gov/pmc/articles/PMC2585760/

[13] Y. Nie.聶亞寧.從体驗論看漢語“吃”的轉喻和隱喻認知 模式 Cóng tǐyàn lùn kàn hànyǔ “ch "̄” de zhuăn yù hé yǐnyù rènzhī móshì 'On the Metonymy and Metaphorical Cognitive Mode of Chinese "Eating" from the Perspective of Experience Theory' , 2009. Online available from http://big.hi138.com/wenxueyishu/hanyuwenxue/200901/7 2306.asp\#.Wz4_StJKhkg

[14] J.Newman. The Linguistics of Eating and Drinking,Amsterdam/Philadelphia: John Benjamins Publis hing Company, 2009.

[15] V. Gallese, G. Lakoff. The Brain's Concepts: The Role of the Sensory- Motor System in Conceptual Knowledge. Cognitive Neuropsychology: 22, 455-479, 2005. Online available from Doi: 10.1080/0264329044200310. 